Contar desde la trinchera, lo que el virus nos legó. Relatos en primera persona

Gustavo Melfi

Question/Cuestión, Nro.70, Vol.3, diciembre 2021

ISSN: 1669-6581

URL de la Revista: https://perio.unlp.edu.ar/ojs/index.php/question/

IICom -FPyCS -UNLP

DOI: $\underline{\text { https//doi.org/10.24215/16696581e599 }}$

\title{
Contar desde la trinchera, lo que el virus nos legó
}

\section{Relatos en primera persona}

\section{Gustavo Melfi}

Universidad Nacional de La Plata

Argentina

gustavojaviermelfi@gmail.com

A principios del año 2020, una pandemia se nos puso por delante y el mundo cambió. En ese nuevo contexto nuestra labor como docentes debió amoldarse a los nuevos desafíos que se requerían, así como tantas otras y otros trabajadores de diversas profesiones lo hicieron también a lo largo y ancho del globo por donde este virus logró expandirse.

La experiencia del armado y composición de este libro, recorre algunos pensamientos previos que comenzaron mucho antes de iniciar con el proyecto, y que nos lleva al comienzo de la pandemia en marzo del 2020, en ese momento era solo una idea impulsada por la necesidad de querer expresar algo que estábamos atravesando como sociedad y el mundo era testigo, algo sobre lo que no había mucha certeza, solo el cuidado personal, la higiene y el aislamiento social. 
Esa necesidad impulsó la creación de un libro de carácter digital, con el aporte de varios profesionales, todos ellos comprometidos desde sus disciplinas con la educación pública, inclusiva y de calidad.

En ese marco, nació "Contar desde la trinchera”, que es un conjunto de relatos en primera persona, compuesto por diversos profesionales que se desempeñan en distintos ámbitos, desde la educación, la salud, el Estado y la cultura entre otros. Es un trabajo que pretende mostrar algunas realidades que no son visibles, que no aparecen en los medios masivos de comunicación por distintos intereses, y que muchas veces se opaca todo el esfuerzo realizado por distintos sectores de la sociedad, con noticias instaladas e impuestas según las agendas mediáticas.

En este sentido, pretendimos que fueran muchas las voces que puedan contextualizar estas realidades tan disimiles y nos propusimos mostrar y contar con aquellas voces que menos se ven, pero que han aportado mucho al combate contra el COVID-19 de una forma silenciosa.

Uno de los propósito de este libro, ha sido poder reflexionar sobre algunas de las nuevas prácticas que se han ido desarrollando en el contexto de pandemia, y poder contribuir ayudando a visibilizar algunos de esos procesos, unificándolos, repensando los lugares comunes, y reflexionando sobre aquellas nuevas formas y alternativas que debieron resignificarse para dar continuidad a distintas tareas y responsabilidades.

Aquí el rol de la comunicación ha sido fundamental durante todo el proceso de construcción, pensada como herramienta constitutiva de los procesos sociales, culturales y simbólicos, en un momento sin precedente, donde un marcado posicionamiento político y económico resulta indispensable para hacer base en el bien común. Estas prácticas simbólicas se ven atravesadas de diversas maneras, y lo hacen al mismo tiempo en que transcurren las experiencias e innovaciones tanto individuales como colectivas, que son parte de un contexto mundial que no da respiro. 
No es posible hablar de prácticas aisladas, por el contrario son transversales en todas sus dimensiones, por ello la idea de incluir diferentes miradas y reflexiones de distintas especialidades, sobre todo aquellas que han estado en el campo de batalla como el equipo de salud, pero también lo ha hecho la educación asumiendo compromisos sumamente necesarios.

\section{Recopilación de las producciones}

A lo largo de estos meses, luego de la propuesta inicial para escribir esta producción, fueron llegando distintos trabajos, de diferentes estilos, con diversos recorridos, trayectorias, especialidades, muchas fuertes, todas sinceras, algunas más formales, otras con mucho sentimiento, algunas más académicas, y todas ellas con la finalidad de contar y las ganas de decir. La pregunta era cómo ordenábamos todo eso en una producción, cómo entrelazábamos los distintos estilos, cómo organizábamos las diversas temáticas, y la respuesta no tardó en llegar: el propósito de esta producción era contar desde nuestras realidades, cómo fue y cómo nos atravesaba día a día el contexto de pandemia, y la realidad es que nos pasó por todos lados. Por eso se tomó la decisión de ordenarlos por ejes temáticos respetando la impronta y estilo de sus autores.

Todos esos relatos debían ser ordenados bajo cierta lógica, para que quien lea estas experiencias cuente con una especie de organización, un mapa que ayude a orientar por dónde ir con la lectura, y con qué se puede encontrar según sus partes: la primera parte, "En la trinchera no paramos", está compuesta por las voces de aquellos trabajadores que vivieron la experiencia de la pandemia en primera línea y que nos transmiten algo de esa intensidad, que se vivió en los hospitales y los diversos cuidados del equipo de salud, pasando por el vínculo y el lazo social, que debió reinventar la escuela como institución. En "Apuntes y reflexiones" nos lleva a algunas de las discusiones, experiencias y acercamientos críticos que fueron posibles por esta situación excepcional de pandemia, en campos como el de la educación, la economía y el medioambiente. En la tercera parte, "Repensar la educación", se abre un espacio para los debates, las incertidumbres y las experiencias de una de las áreas en las que el virus desplegó mayor influencia y cuestionamientos, y que posibilito repensar nuevas formas de hacer, de 
entrelazar, de incluir y a su vez revisar prácticas. En "Relatos atravesados" distintos autores y autoras ponen en palabras la experiencia de la pandemia bajo distintas formas literarias, lleno de subjetividades, plagados de sentimientos literalmente atravesados. La última parte, titulada "Cómo seguimos", nos da la posibilidad de conocer algunas ideas surgidas en aislamiento, la importancia de la alimentación sana, organización y otras formas de hacer, que apuestan a nuevas formas de habitar y entender el mundo.

La realidad de la pandemia fue que nos pasó por encima, y nos atravesó desde distintos lugares, por todos lados y así nació esta producción llena de subjetividades, compuesta por múltiples voces con ganas de decir, Contar desde la trinchera, lo que el virus nos legó, ha sido la manera que muchos y muchas encontramos para exteriorizar y visibilizar pequeños universos y tratar de mejorarlos, empatizar con aquellos que más sufrieron y haciendo siempre hincapié en la construcción colectiva.

Utopía o no, por ahí intentamos ir.

Contar desde la trinchera : lo que el virus nos legó / Gustavo Javier Melfi ... [et al.]. - 1a ed - La Plata : Gustavo Javier Melfi, 2021. 208 p. ; 23 x 15 cm. ISBN 978-987-88-1236-6

1. Memorias. I. Melfi, Gustavo Javier

CDD A863

\section{Redes y link del libro digital}

https://contardesdelatrinchera.blogspot.com/

https://www.instagram.com/invites/contact/?i=1dtvfaumkvle1\&utm content=kuh2zla 
Question/Cuestión, Vol. 3, № 70

Diciembre 2021

ISSN 1669-6581

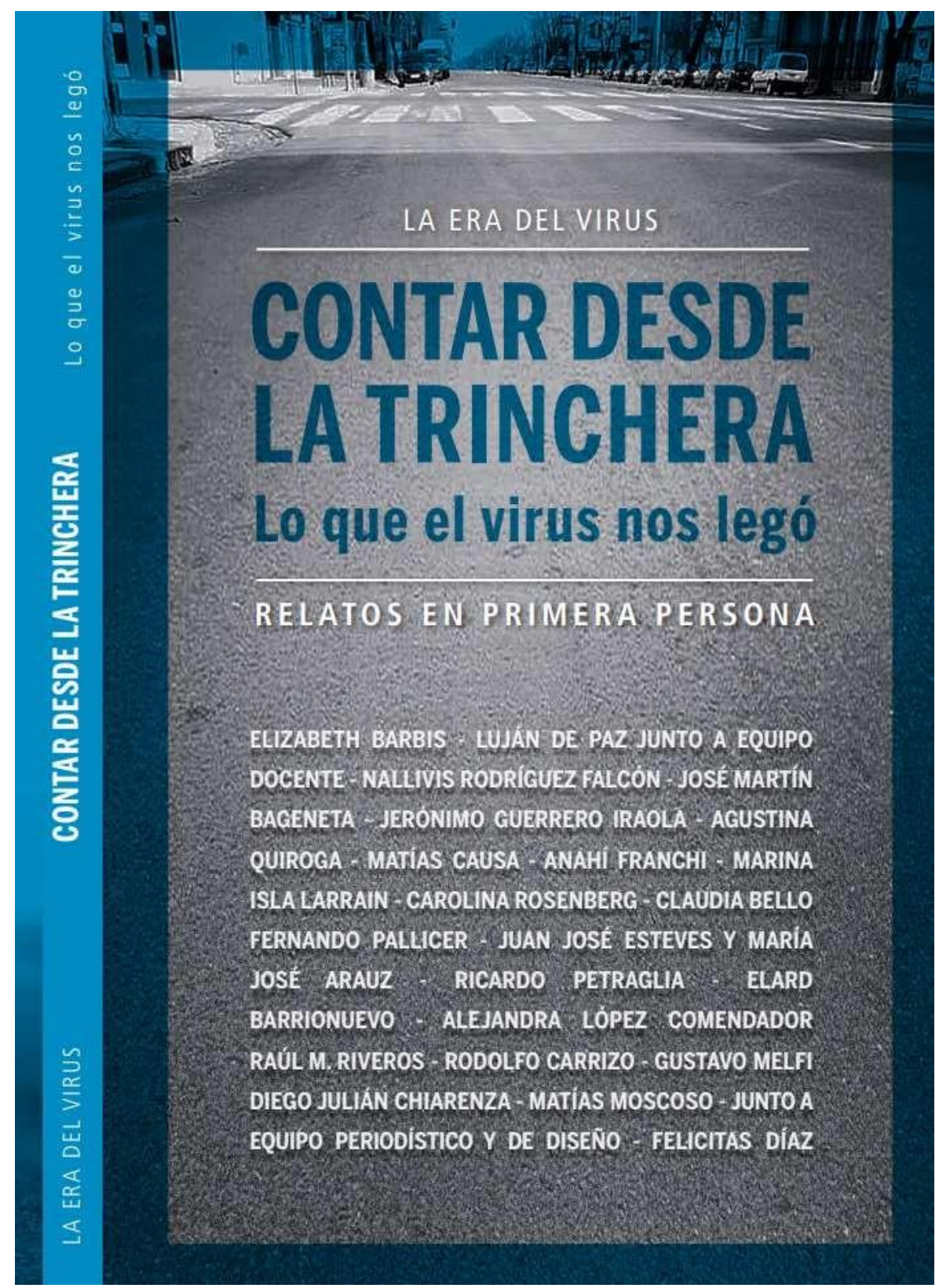

IICom (Instituto de Investigaciones en Comunicación)

Facultad de Periodismo y Comunicación Social

Universidad Nacional de La Plata 
Question/Cuestión, Vol. 3, № 70

Diciembre 2021

ISSN 1669-6581

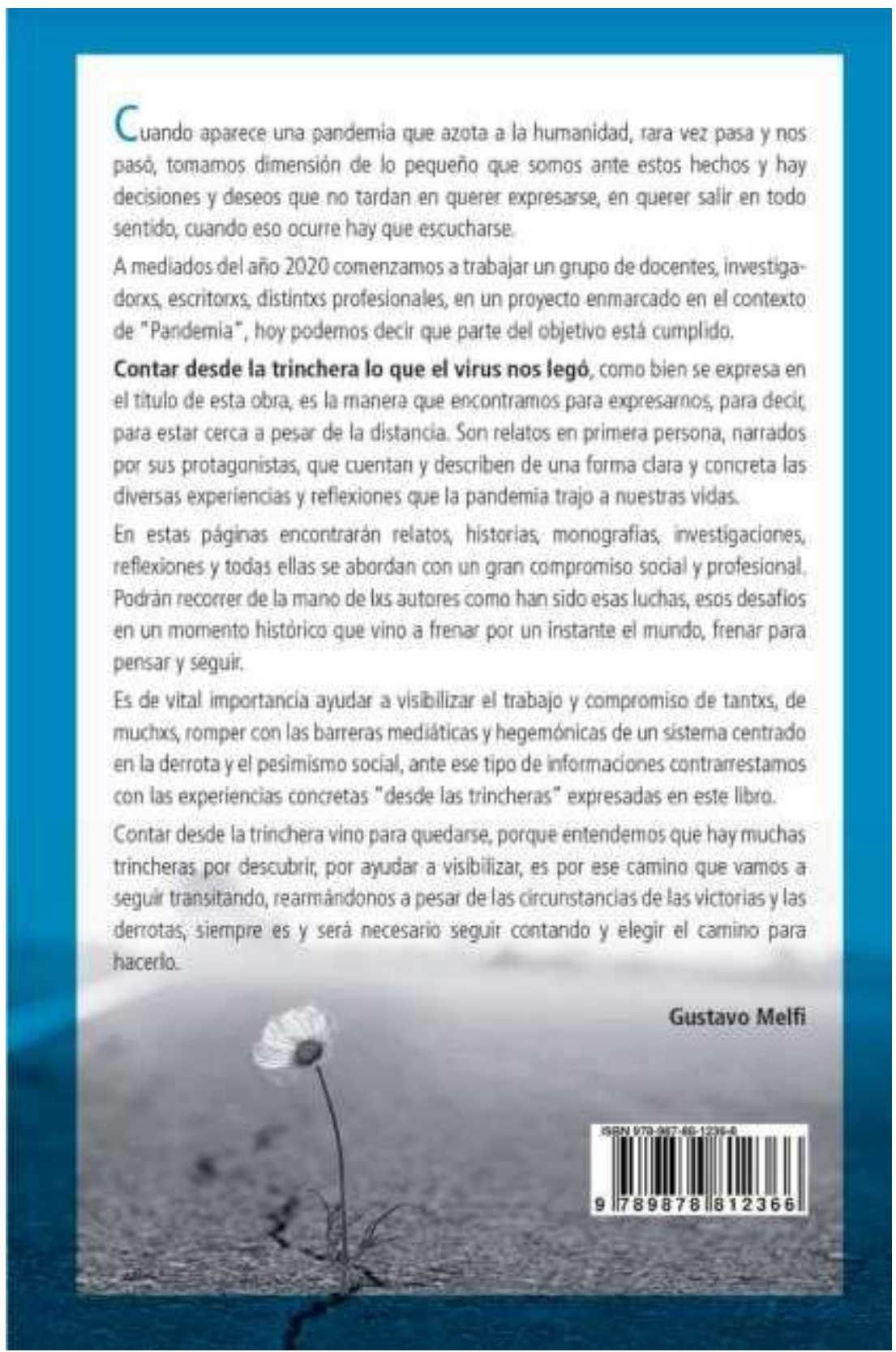

IICom (Instituto de Investigaciones en Comunicación)

Facultad de Periodismo y Comunicación Social

Universidad Nacional de La Plata 
Question/Cuestión, Vol. 3, № 70

Diciembre 2021

ISSN 1669-6581

Dedicado a todas las personas que se llevó este

virus,

a sus familiares y amigos, y a todos aquellos que resisten, y cada dia dan pelea desde sus trincheras. 